\title{
Current safety preferences for intravitreal injection during COVID-19 pandemic
}

\author{
Or Shmueli ${ }^{1} \cdot$ Itay Chowers ${ }^{1} \cdot$ Jaime Levy (1) $^{1}$
}

Received: 31 March 2020 / Revised: 17 April 2020 / Accepted: 22 April 2020 / Published online: 4 May 2020

(c) The Royal College of Ophthalmologists 2020

The new Corona virus disease (COVID-19) pandemic is caused by SARS-CoV-2, a single-stranded RNA virus. Human-to-human transmission occurs mainly by air droplets up to 1-m distance and contact with contaminated surfaces or hands [1,2]. The virus is effectively inactivated by ethanol and chlorine-containing disinfectants [3].

Intravitreal injections (IVI) have become the most commonly performed ophthalmic procedure. Patients requiring IVI therapy are often at increased risk for complications associated with COVID-19 given their age and comorbidities. These patients can pass through multiple stations in clinics, including the reception, waiting halls, visual acuity testing room, imaging suite, physician, and injection rooms. In addition, slit-lamp examination and the injection procedure itself expose both patient and treating physician as they create a close face-to-face contact between them. All the above, combined with the current high volume of IVI, poses a significant public health risk for COVID-19 transmission. Conversely, withholding IVI can cause irreversible vision loss in some patients.

\section{Rescheduling of patients}

In cases where delaying injections is not expected to result in substantial visual loss, this may be the preferred option while social distancing is indicated. Yet, social distancing at variable stringency level is likely to stay around for months or even years [4]. Thus, a more realistic goal should be minimizing the number of clinic visits and injections rather than withholding therapy. Cases where prolongation of treatment interval may be practiced more liberally may

Jaime Levy

levjaime@gmail.com

1 Department of Ophthalmology, Hadassah-Hebrew University Medical Center, Jerusalem, Israel include eyes with diabetic macular oedema (DMO) or branch retinal vein occlusion (BRVO) with minimal macular oedema in the last exam according to optical coherence tomography (OCT). In DMO, treat-and-extend regimen (TER) using increase intervals of 1 month was non inferior to pro-re-nata (PRN) protocol, but with $46 \%$ less visit [5]. Delaying IVI in retinal vein occlusion patients to PRN every 12 weeks resulted in visual loss in CRVO patients but not in BRVO patient [6].

Conversely, if the indication is neovascular age-related macular degeneration (NVAMD) or proliferative diabetic retinopathy, delaying injections may be possible in selected cases, such as eyes with NVAMD with poor vision in the treated eye and stable on injection every 3 months. In individuals younger than 60 years of age with no comorbidities associated with severe COVID-19 course, one may decide to proceed with the treatment as planned even in cases where the treatment may be delayed in older patients.

In NVAMD, a fixed 3 months therapy schedule might result in vision loss. Fixed-interval bevacizumab every 4-6 weeks with no OCT monitoring and variable dosing regimens of intravitreal bevacizumab based on OCT monitoring both result in similar improvement in visual acuity and central macular thickness, but with more injections (9.5 vs. 3.8 injections during 1 year follow up) in the fixed treatment group [7, 8]. Thus, an ideal treatment schedule for the COVID-19 era, which minimizes the number of visits while showing non-inferior visual outcome is TER $[9,10]$.

Patients with an urgent indication for injection should be contacted by the registration staff by telephone before the appointment to reschedule patients at quarantine and suspected or confirmed cases of COVID-19. Questions should be asked about isolation status, symptoms or SARS-CoV-2+ individual in the past 14 days. If a patient answer yes to any of the questions, they should be encouraged to speak to their primary care provider and the injection visit should be delayed. If symptoms are severe, they should be sent to the Emergency Department of a hospital capable of handling COVID-19 [11]. Treatment of quarantined or SARS-CoV-2+ 
Table 1 Summary of measures to prevent COVID-19 transmission while maintaining adequate care of intravitreal injections.

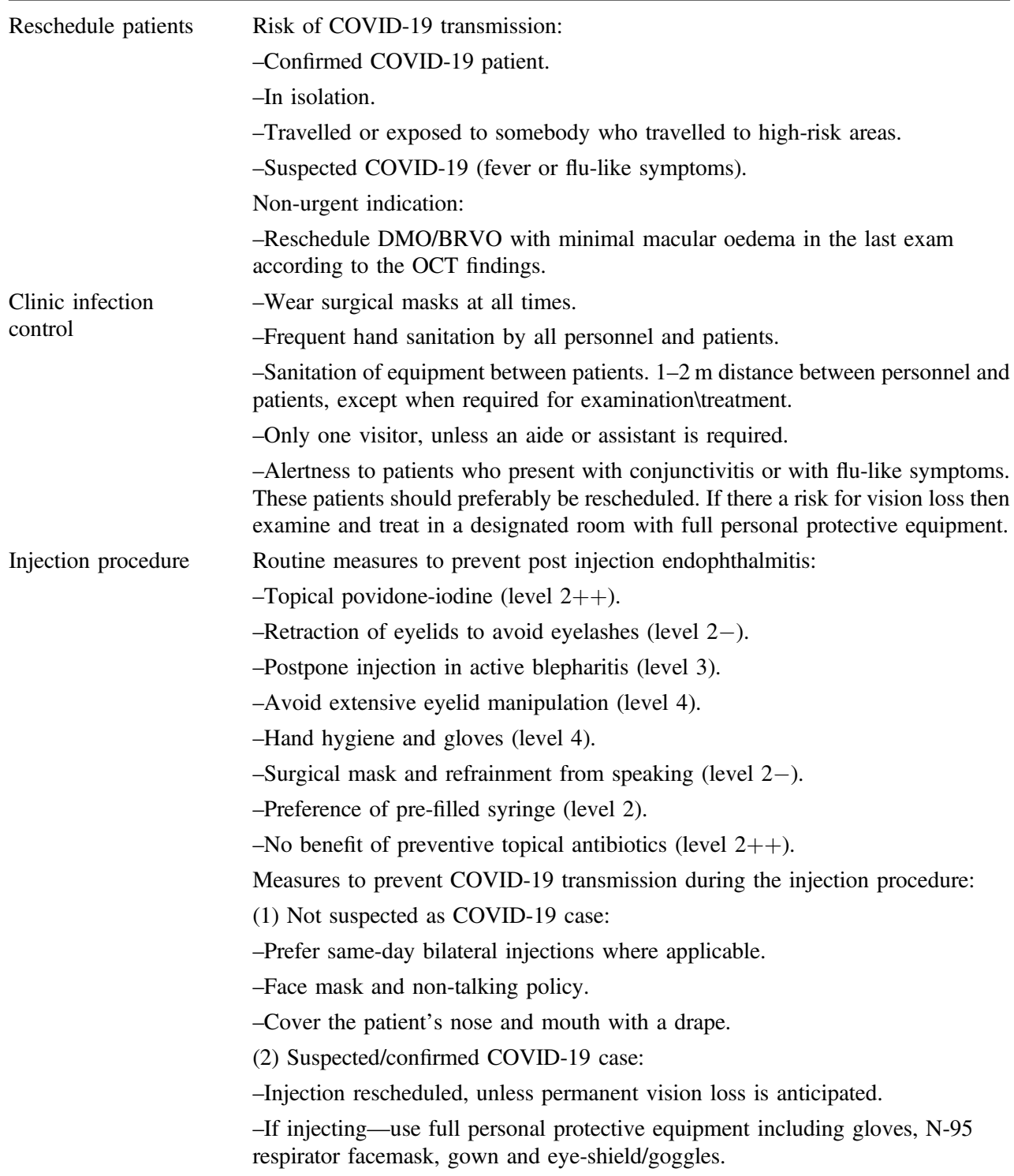

Clinic infection control

-Wear surgical masks at all times.

-Frequent hand sanitation by all personnel and patients.

-Sanitation of equipment between patients. 1-2 m distance between personnel and patients, except when required for examination $\mid$ treatment.

-Only one visitor, unless an aide or assistant is required.

-Alertness to patients who present with conjunctivitis or with flu-like symptoms. These patients should preferably be rescheduled. If there a risk for vision loss then examine and treat in a designated room with full personal protective equipment.

Injection procedure Routine measures to prevent post injection endophthalmitis:

-Topical povidone-iodine (level $2++$ ).

-Retraction of eyelids to avoid eyelashes (level 2-).

-Postpone injection in active blepharitis (level 3).

-Avoid extensive eyelid manipulation (level 4).

-Hand hygiene and gloves (level 4).

-Surgical mask and refrainment from speaking (level 2-).

-Preference of pre-filled syringe (level 2).

-No benefit of preventive topical antibiotics (level $2++$ ).

Measures to prevent COVID-19 transmission during the injection procedure:

(1) Not suspected as COVID-19 case:

-Prefer same-day bilateral injections where applicable.

-Face mask and non-talking policy.

-Cover the patient's nose and mouth with a drape.

(2) Suspected/confirmed COVID-19 case:

-Injection rescheduled, unless permanent vision loss is anticipated.

-If injecting-use full personal protective equipment including gloves, N-95 respirator facemask, gown and eye-shield/goggles.

COVID-19 Corona virus disease 2019, DMO diabetic macular oedema, BRVO branch retinal vein occlusion.

cases should be delayed at this time until the individual will become SARS-CoV-2 negative per to sequential PCR tests. Based on the shedding period of SARS-CoV-2 the delay in providing injection will likely last about 3 weeks or less [12]. Such delay is unlikely to result in substantial visual loss in most cases. Yet, in special cases such as monocular patients or documented rapid loss of sight, one may consider performing IVI in COVID-19+ individuals using the appropriate personal protection equipment and setting.

\section{Infection control in clinics}

All personnel and patients should wear face masks at all times while at the clinic. The CDC recommends N95 masks in routine and high-risk situation, while the WHO recommends using a surgical mask in routine situations and a N95 mask in high-risk situations [13].

Frequent hand-sanitation by all personnel and patients with ethanol-based disinfectants is recommended by the CDC [14]. Meticulous sanitation of examination and treatment equipment (including imaging, examination, and injection rooms) between patients is mandatory. One to two metres' distance should be maintained between individuals present at the clinic including personnel and patients at all times, except when required for examination and treatment. Large protective breath shields should be installed on slit lamps, and exam rooms should be well ventilated. The presence of accompanying individuals should be minimized. All personnel should be on alert for patients 
with conjunctivitis or flu-like symptoms (fever, cough, sore throat, headache, shortness of breath, fatigue, and loss of smell or taste). These patients should be considered at risk for COVID-19 and treated as such. Visit should be rescheduled. If there is vision loss or a risk for vision loss then these patients should be examined and treated in a designated room and the physician should wear full personal protective equipment [11].

\section{Safe injection procedure}

Routine Guidelines for prevention of PIE following IVI have been previously published [15]. SARS-CoV-2 is transmissible by contact and droplets (and aerosol in long-duration contacts or procedures involving the respiratory system such as intubation). Additional considerations should be made for measures to reduce the risk of SARS-CoV-2 transmission during IVI on patients not suspected as COVID-19 case. These may include preference of same-day bilateral injections where possible so patients do not have to return to the clinic; stronger support of usage of face mask for the injecting physician and non-talking policy; preference of drape use to cover patient's nose and mouth $[11,16]$.

Suspected/confirmed COVID-19 case injection should be rescheduled unless permanent vision loss is anticipated. When injecting to a suspected/confirmed COVID-19 case it is prudent to use full personal protective equipment including gloves, N-95 respirator facemask, gown, and eyeshield/goggles [11].

Table 1 provides a summary of measures to prevent COVID-19 transmission.

\section{Compliance with ethical standards}

Conflict of interest The authors declare that they have no conflict of interest.

Publisher's note Springer Nature remains neutral with regard to jurisdictional claims in published maps and institutional affiliations.

\section{References}

1. van Doremalen N, Bushmaker T, Morris DH, Holbrook MG, Gamble A, Williamson BN, et al. Aerosol and surface stability of SARS-CoV-2 as compared with SARS-CoV-1. N Engl J Med. 2020;382:1564-7.

2. Liu J, Liao X, Qian S, Yuan J, Wang F, Liu Y, et al. Community transmission of severe acute respiratory syndrome coronavirus 2 ,
Shenzhen, China, 2020. Emerg Infect Dis. 2020;26. https://doi. org/10.3201/eid2606.200239.

3. Cascella M, Rajnik M, Cuomo A, Dulebohn SC, Di Napoli R. Features, evaluation and treatment Coronavirus (COVID-19). In: StatPearls. Treasure Island (FL): StatPearls Publishing; 2020.

4. Adam D. Special report: the simulations driving the world's response to COVID-19. Nature. 2020;580:316-8.

5. Prünte C, Fajnkuchen F, Mahmood S, Ricci F, Hatz K, Studnička $\mathrm{J}$, et al. Ranibizumab $0.5 \mathrm{mg}$ treat-and-extend regimen for diabetic macular oedema: The RETAIN study. $\mathrm{Br} \mathrm{J}$ Ophthalmol. 2016;100:787-95.

6. Heier JS, Campochiaro PA, Yau L, Li Z, Saroj N, Rubio RG, et al. Ranibizumab for macular edema due to retinal vein occlusions: long-term follow-up in the HORIZON trial. Ophthalmology. 2012;119:802-9.

7. Schmidt-Erfurth U, Eldem B, Guymer R, Korobelnik JF, Schlingemann RO, Axer-Siegel R, et al. Efficacy and safety of monthly versus quarterly ranibizumab treatment in neovascular age-related macular degeneration: the EXCITE study. Ophthalmology. 2011;118:831-9.

8. El-Mollayess GM, Mahfoud Z, Schakal AR, Salti HI, Jaafar D, Bashshur ZF. Fixed-interval versus OCT-guided variable dosing of intravitreal bevacizumab in the management of neovascular age-related macular degeneration: a 12-month randomized prospective study. Am J Ophthalmol. 2012;153:481-489.e1.

9. Silva R, Berta A, Larsen M, Macfadden W, Feller C, Monés J. Treat-and-extend versus monthly regimen in neovascular agerelated macular degeneration: results with ranibizumab from the TREND study. Ophthalmology. 2018;125:57-65.

10. Wykoff CC, Ou WC, Brown DM, Croft DE, Wang R, Payne JF, et al. Randomized trial of treat-and-extend versus monthly dosing for neovascular age-related macular degeneration: 2-year results of the TREX-AMD study. Ophthalmol Retin. 2017;1:314-21.

11. Chen R, Rapuano C, Coburn A, Ostrovsky A, Justin GA, et al. American Academy of Ophthalmology update on COVID-19. 2020. https://eyewiki.aao.org/Coronavirus_(COVID-19)\#cite_ note-22).

12. Zhou F, Yu T, Du R, Fan G, Liu Y, Liu Z, et al. Clinical course and risk factors for mortality of adult inpatients with COVID-19 in Wuhan, China: a retrospective cohort study. Lancet. 2020;395:1054-62.

13. Chughtai AA, Seale H, Islam MS, Owais M, Macintyre CR. Policies on the use of respiratory protection for hospital health workers to protect from coronavirus disease (COVID-19). Int J Nurs Stud. 2020;105:103567.

14. Centers for Disease Control and Prevention (CDC) site. Coronavirus Disease 2019 (COVID-19). National Center for Immunization and Respiratory Diseases (NCIRD), Division of Viral Diseases. 2020. https://www.cdc.gov/coronavirus/2019-ncov/ca ses-updates/summary.html?CDC_AA_refVal $=$ https $\% 3 \mathrm{~A} \% 2 \mathrm{~F} \%$ 2Fwww.cdc.gov\%2Fcoronavirus\%2F2019-ncov\%2Fsummary. html.

15. Avery RL, Bakri SJ, Blumenkranz MS, Brucker AJ, Cunningham ET, D'amico DJ, et al. Intravitreal injection technique and monitoring: updated guidelines of an expert panel. Retina. 2014;12: S1-S18.

16. McGrath D. SFO issues injection guidelines in light of the COVID-19 epidemic. 2020. https://www.eurotimes.org/sfoissues-injection-guidelines/. 